Canadian Journal of Family and Youth, 13(3), 2021, pp. 371- 377

ISSN 1718-9748@ University of Alberta

http://ejournals,library,ualberta.ca/index/php/cjfy

\title{
Invisible Abuse Among Invisible Citizens
}

\author{
Brey Dawson, MacEwan University
}

\section{Introduction}

Child abuse has always been pervasive in society. However, with recent forced isolation orders due to COVID-19, it could be getting much worse. Child abuse generally includes four types: physical abuse, sexual abuse, emotional abuse, and neglect (Tuscic, Flander, \& Mateskovic, 2013). This essay will examine the potential negative consequences associated with the confinement on children at risk for physical, sexual, and emotional abuse. Due to the restrictions of services that scan for abuse, such as hospitals, schools, and social workers, it is argued that child abuse will increase.

\section{Child Abuse vs Corporal Punishment}

The Canadian Red Cross defines child abuse as "any form of physical, emotional and/or sexual mistreatment or lack of care that causes injury or emotional damage to a child or youth" (Canadian Red Cross, 2021). Researchers estimate around 275 million children worldwide suffer from domestic abuse, but the numbers could be much higher due to underreporting (Roca, Melgar, Gairal-Casado, \& Pulido-Rodriguez, 2020). Before the age of 14, roughly $28 \%$ of children have experienced child abuse, and of that population, $95 \%$ have experienced more than one form of abuse (Tuscic, Flander, \& Mateskovic, 2013).

Physical abuse is harming an individual until it causes a physical injury, such as beating, strangulation, or burning. The definition of sexual assault for children and adults slightly differs. For children, sexual assault can either be between an adult and a minor or two minors if the abuser has some form of power over the victim. Sexual assault to a minor also covers contactless sexual acts such as being forced to watch pornography, exposure to genitals, or communication for sexual gratification. The Council of Europe has estimated that one out of five children have been sexually abused (Tuscic, Flander, \& Mateskovic, 2013).

Emotional abuse is a negative, repetitive behaviour customarily displayed by a parent or guardian to degrade a child. This behaviour can be non-responsive, such as disregarding the child's existence. Alternatively, it can be more cavillous and aggressive, such as saying the child is useless 
or unloved by the family. Because emotional abuse is unique to the individual, it is difficult to estimate the exact number of cases, but it is thought to be the most common form of abuse (Tuscic, Flander, \& Mateskovic, 2013).

A copious amount of discourse centers around what is considered abuse versus corporal punishment (CP). Corporal punishment is "the use of physical force with the intention of causing a child to experience pain, but not injury, for the purpose of correction or control of the child's behaviour" (Straus \& Stewart, 1999, p. 57). In the United States, the crime of assault can be exempted from parents if they are using CP for "correction and control" (Straus \& Stewart, 1999, p. 57).

Since there is technically a difference between corporal punishment and abuse, it is important to screen the prevalence, chronicity, severity, and punishment style duration. CP's prevalence is the variation of acts, such as being spanked with a hand or object, shook, or slapped on the face, hand, or leg. If a child under age three is shaken by a parent, it may be considered abuse and have severe consequences. Chronicity is how often the child is being punished using these techniques. If it is constantly happening regardless of behaviour, CP could be treated as abuse. Severity is more based on whether the act is expressed as normal to society, such as a spanking. Society would be less accepting of slapping the child in the face or hitting them with an object. Conversely, a hard spanking might be overlooked because society deems it acceptable, even though it is damaging to the child. Duration is how long the punishment exists in the child's life. CP starts to fade around 12 years old for most children (Straus \& Stewart, 1999).

The main difference between the two definitions is that one causes injury, while the other is only supposed to direct pain. However, both may elicit emotional damage depending on factors like severity or chronicity (Straus \& Stewart, 1999). While sexual abuse is not under the umbrella definition of CP, emotional and physical abuse could be. The difference is equivocal and should be discouraged to prevent an array of consequences.

\section{Consequences}

Concerning child abuse, there are two significant consequences: short-term and long-term. Short-term consequences develop right after the abuse occurs and may even manifest into longterm consequences if severe enough. The most tragic consequence is death, and a conservative estimate shows that over 2000 children in the USA alone die from abuse every year (Tuscic, Flander, \& Mateskovic, 2013). Of those deaths, 80 percent are children under the age of five, and 40 percent under one (Bethea, 1999).

Physical abuse is one of the most dangerous forms because it could result in death. However, most research on child abuse focuses on the connections between physical abuse and aggressive or delinquent behaviour. Children physically abused before the age of five tend to be more aggressive than their peers. More aggressive anti-social behaviour tends to arise alongside physical punishment, as well as lower internalization of moral standards and poor self-esteem. Social withdrawal could be damaging for forming relationships inside and outside of the house. Having positive relationships, away from the abuser, are one of the best predictors for a successful recovery (Tuscic, Flander, \& Mateskovic, 2013). 
Children who have been sexually abused — especially those with prolonged exposure - are more likely to have noticeably poorer health than those who have not been abused. The four main contributors to serious symptoms are the duration, severity, violence, and the child's emotional proximity to the abuser. Children who are sexually abused by their biological parents are the least likely to recover successfully. The younger the child is when sexual abuse starts, the more severe the symptoms become because it is likely that the abuse will last longer and take on more forms. Sexual abuse during childhood, specifically with young girls, leads to various psycho-pathological disorders such as eating disorders, insomnia, depression, self-harm, and low self-confidence. Many of these psychological issues are due to unresolved conflict, unhealthy coping mechanisms, underdeveloped communication skills, and a weak social support system (Tuscic, Flander, \& Mateskovic, 2013).

Emotional abuse is chronically unreported because it is less obvious to detect in a clinical setting than a physical ailment like a bruise or burn. Instead, it usually takes the form of verbal aggression like name-calling, belittling, and persistent yelling. The long-term effects of emotional abuse are psychological and lead to mood disorders and mental illness. Children who have experienced emotional abuse tend to have higher levels of depression and anxiety than those with non-aggressive parents (Lippard \& Nemeroff, 2020).

\section{Increase of Child Abuse During COVID-19}

Isolation is a well-known risk for child abuse as it frequently happens during summer breaks, holidays, and natural disasters (Caron, Plancq, Tourneux, Gouron, \& Klein, 2020). This increased risk is because child protection services become temporarily unavailable or are only used for emergencies. During the lockdown periods in France brought on by Coronavirus, child abuse reporting decreased. However, the decrease was not because of abuse coming to a halt; rather, it reflected the halt on protective programs. In-person meetings with social workers were suspended, schools and daycares for disabled children were temporality closed, and hospitals took $70 \%$ fewer appointments for children. This decrease in reporting reflects the lack of screening being done (Caron et al., 2020).

Data was collected on 31 children admitted to the emergency department at Amiens University Hospital in France during the lockdown period. Out of those children, "16 supervision orders and ten interim care orders" were placed, along with seven children being temporarily put into foster care (Caron et al., 2020). Evidently, children are being abused, but are only screened during emergencies.

Past research has shown that CP is used chronically by parents who have two-year-olds (Straus \& Stewart, 1999). The first three years of life are the most important for brain development (Bethea, 1999). Some of the long-term effects of physical abuse are problems with the brain, such as irregular speech or emotional development, hyperactivity, and problems sleeping (Tuscic, Flander, \& Mateskovic, 2013). If a child were being abused before COVID-19, they may already have these problems, which could be mistaken as misbehaving. The inability of a child to voice their wants or needs is frustrating for everyone. The child may cry or throw a tantrum because it is the only semi-effective communication technique they know. A child's hyperactivity and refusal 
to sleep may be interpreted as fooling around or not listening, aggravating an already shorttempered parent. Behaviours that accompany these cognitive disabilities could strain parents who are not equipped to deal with it, turning to $\mathrm{CP}$ or physical abuse to handle the situations.

\section{Primary Prevention During COVID}

Primary prevention is "both the prevention of disease before it occurs and the reduction of its incidence" (Bethea, 1999, para. 3). It is essential to recognize risk factors to prevent abuse from happening and intervene when it occurs to reduce its significance. Previous prevention tactics for child abuse were static. They only considered a limited number of reasons why parents would abuse their child, making it a terrible predictor for future abuse. The new system is called the ecologic model, and it recognizes that child abuse is complex (Bethea, 1999). This model evaluates risk and protective factors across four levels: the individual, the family, the community, and the society.

Some risk factors for the individual (child) are prematurity and disability. These are most likely risk factors because health complications with the child can be stressful with parents emotionally and financially. Risks for the family (parents) include the parents' history of abuse, poor coping skills, and lack of preparation for the child. Parents who have been abused tend to repeat the cycle if they have not learnt the proper coping mechanisms to handle their trauma. Lacking fundamental parental skills can push parents in the wrong direction regarding punishment, which leads to child abuse (Bethea, 1999).

The community and society factors include high crime rate, lack of social services, and high poverty rate. In the United States, deadly violence is higher than 17 other developed countries, including Canada. Three-quarters of that violence is coming from abusive households. Poverty is consistent with child abuse because of factors like stress, unaffordable health care, and lack of support from extended family. It is thought that if social challenges such as these are confronted, it will be the most significant help for tackling domestic abuse (Bethea, 1999).

Some social intervention for preventing abuse is increasing the value of children and discouraging corporal punishment, making families more economically efficient and having accessible health care, and increasing community resources, such as drug prevention and mental health treatment centers. Strengthening the family and community shows the highest success rates for preventing child abuse. If resources are poured into the parents, it will provide a safer and happier life for the children whom they are raising. If a parent's basic needs are not being met, then neither will the child's. Organizing drug treatment and mental health centers are the first steps. Next is education. If parents are taught how to manage stress, budget money, and learn proper parenting skills, their lives will become more successful (Bethea, 1999).

If the abuse cannot be stopped from the beginning, new measures need to be introduced to help children cope with their trauma. Throughout March, April, and May of 2020, the French government ran an awareness campaign through television, newspapers, and social media for domestic violence. During this campaign, the national child abuse hotline saw an $89.4 \%$ increase in calls (Caron et al., 2020). This strategy was effective at detecting abuse that would not have been diagnosed until after the lockdown. Technology and advertising helped reach children 
without resources like a social worker accessible to them while in isolation. However, children around the age of two are the most likely to get physically abused because of increased misbehaving during toddlerhood (Straus \& Stewart, 1999). They are not old enough to use a phone. Home visits by social workers are the most effective in reducing child abuse and need to stay active for toddlers (Bethea, 1999). Wearing protective equipment such as a face mask and using hand sanitizer will make the visits safe for everyone (Caron et al., 2020).

One evidence-based study was carried out in nine different schools, seven of which were pre-schools or primary schools, to co-create a process to help children who are being abused. This study was a communicative approach where teachers, principals, and school counsellors explain their experience with the Open Doors Action program (ODA) (Roca et al., 2020). Teachers repeatedly notice anxious and overly shy behaviour amongst students who were being abused (Tuscic, Flander, \& Mateskovic, 2013). Teachers must be prepared with the skills to notice such red flags. Through a series of three focus groups, they assessed how well ODA worked during isolation periods (Roca et al., 2020). Through the ODA program, these schools' actions were: dialogic workspaces, dialogic gatherings, class assemblies, dialogic pedagogical gatherings, mixed committees, and dynamization of social networks to create a community through preventive messages.

Dialogic workspaces are video conferences between students and teachers. Traditionally, a student's home is a private space, but ODA creates a new environment with other students through video conferences. Four out of nine schools used this technique. One principal said, "having a dialogic space that gives purpose motivates and cheers them up. It allows us to open up a public space in their homes" (Roca et al., 2020, pp. 8). Dialogic gatherings help keep humanity active on video conferences by discussing things like music, literature, and art. Students can present how they interpret specific artwork and their passions. One teacher explains, "We talk about very important issues that the children are concerned with now during confinement and what is going on in an egalitarian environment of absolute respect so that they feel free to tell how they feel. The rest of the people usually offer advice and assistance as it is a space in which we promote solidarity" (Roca et al., 2020, pp. 9). Seven schools used this technique.

Class assemblies are usually run by a teacher who presents topics like abuse or violence to help start a dialogue amongst the students (Roca et al., 2020). The teachers felt like this was important to keep even on video conference because it allows students to share their home life and relationships. One principal said, "It is important that the assemblies go on in order to report violence, to allow them to express how they are living these days, about the relations of friendship and maybe to have a space to report violence" (Roca et al., 2020, pp. 9). Five schools kept assemblies active during the lockdown. Dialogic pedagogical gatherings were the least used by the schools; only two thought they were helpful. Teachers would read relevant theories published by scientific journals (Roca et al., 2020). This technique would be too advanced for younger students and children with mental disabilities.

Mixed communities would include parents and other community members. This approach was extremely helpful in building relationships between parents and the schools, providing resources to families like food or scholarships, distribute electronic devices to families that could not afford them, and ensure the child is safe from violence. Parents did not have to feel ashamed 


\section{Dawson}

or embarrassed of their situations. The schools invited them to help with lunch programs and volunteer, making them feel like part of the community. Six schools found this valuable. Last was the use of social networks to create community among the students. This method worked the best for students and spreading awareness, so every school used it. Students would write messages like, "are you overwhelmed by the situation? Do you need us to help you out? What is worrying you? We are here <3" (Roca et al., 2020, pp. 11). The communication between students was an excellent resource for bystander intervention which drastically reduces violence and abuse (Roca et al., 2020).

The Open Doors Action program helps keep school an active agent in preventing abuse (Roca et al., 2020). It promotes learning with a sense of community and love. Schools can be a haven for children who have a rocky home life. Suppose COVID-19 is preventing them from staying open full-time. In that case, researchers, educators, politicians, and other professionals need to develop ways to keep at-risk kids interacting with their community and hopefully their parents. If teachers feel ill-equipped to help screen some of these children, trained nurses or a reliable health care worker needs to be brought in to teach them (Gardner, Derouin, Brown, \& Johnson, 2020).

\section{Conclusion}

Forced isolation of COVID-19 is going to happen regardless of other consequences. Physical, sexual, and emotional abuse have always been rampant in society, but if proper precautions are not taken, it is going to escalate faster than ever before. The consequences of abuse are too severe to ignore. It is essential for services such as social workers and schools to take initiative and find alternatives to prevent abuse from happening. The close contact of social work leaves it as less of an option. However, schools that have the proper funding to provide at risk families with resources to help keep their children in school is the best alternative. Creating a safe and secure place, away from harm, is going to show the best results for recovery. 


\section{References}

Bethea, L. (1999). Primary prevention of child abuse. American Academy of Family Physicians, 59(6), 1-17.

Canadian Red Cross. (2021, March 24). Definitions of child abuse and neglect. Retrieved from Canadian Red Cross: https://www.redcross.ca/how-we-help/violence-bullying-and-abuseprevention/educators/child-abuse-and-neglect-prevention/definitions-of-child-abuse-andneglect

Caron, F., Plancq, M. C., Tourneux, P., Gouron, R., \& Klein, C. (2020). Was child abuse underdetected during the COVID-19 lockdown? (Vol. 27). In Archives de Pediatrie (pp. 399-400). Amsterdam: Elsevier.

Gardner, S. L., Derouin, A., Brown, R., \& Johnson, D. (2020). At the front lines: Effectively training communitu stakeholders to recognize and report child abuse and neglect. The Journal of School Nursing, 36(3), 181-186.

Lawson, M., Peil, M. H., \& Simon, M. (2020). Child Maltreatment during the COVID-19 Pandemic: Consequences of Parental Job Loss on Psychological and Physical Abuse Towards Children (Vol 110, pp. 1-12). In Child Abuse \& Neglect. Amsterdam: Elsevier.

Lippard, E. T., \& Nemeroff, C. B. (2020). The devastating clinical consequences of child abuse and neglect: Increased disease vulnerability and poor treatment response in mood disorders. The American Journal of Psychiatry, 177(1), 20-36.

Roca, E., Melgar, P., Gairal-Casado, R., \& Pulido-Rodriguez, M. A. (2020). Schools that 'open doors' to prevent child abuse in confinement by COVID-19. Sustainability, 12(11), 1-17.

Straus, M. A., \& Stewart, J. H. (1999). Corporal punishment by American parents: National data on prevalence, chronicity, severity, and duration, in relation to child and family characteristics. Clinical Child and Family Psychology Review, 2(2), 55-70.

Tuscic, S. J., Flander, G. B., \& Mateskovic, D. (2013). Consequences of childhood abuse. Paediatrics Today, 9(1), 24-35. 